\title{
Magnesium isotope fractionation during mantle partial melting
}

\author{
XIAONING LIU, REMCO HIN, CHRISTOPHER D. COATH \\ AND TIM ELLIOTT \\ University of Bristol \\ Presenting Author: x117349@bristol.ac.uk
}

Since $\mathrm{Mg}$ is both a dominant constituent of the mantle and a compatible element, its isotopic composition in primitive melts should provide a new perspective on long-debated lithological variability in the sources of oceanic magmas. Although previous research [1] suggested limited $\mathrm{Mg}$ isotope fractionation during partial melting, significant $\mathrm{Mg}$ isotope differences between mantle minerals has been theoretically predicted (e.g.,[2]) and empirically determined (e.g.,[3]), suggesting some scope for magmatic $\mathrm{Mg}$ isotope fractionation. Here, we measured the intermineral $\mathrm{Mg}$ isotope fractionation to higher precision than before, and importantly link this to melting via determining the Ol-melt fractionation factor using natural Ol-glass pairs.

We employed critical mixture double spiking [4] which enables high-precision (2se of 0.01 to $0.02 \%$ ) and comparable accuracy. Separated minerals from mantle peridotites show significant and consistent fractionations from olivine with lowest $\delta^{25} \mathrm{Mg}(\sim-0.13 \%$ o $)$ to spinel with the heaviest values $(\sim 0.02 \%$ o). Our results are consistent with previous less precise measurements and theoretical calculations [2,3]. Meanwhile, natural Ol-glass pairs picked from MORB sample were measured to further constrain the melt-olivine fractionation factor. These reaffirm the ${ }^{25} \mathrm{Mg}$ ol/glass value $(0.999960 \pm 0.000013)$ of our previous work [5], validating this vital but previously poorlyconstrained number.

By applying these newly determined fractionation factors, we modelled $\mathrm{Mg}$ isotope fractionation during partial melting of the mantle. Melts from peridotite are anticipated to have slightly elevated $\delta^{25} \mathrm{Mg}$ values (about 0.01 to $0.02 \%$ ) as a result of olivine preferring lighter $\mathrm{Mg}$ isotopes than melt. The $\delta^{25} \mathrm{Mg}$ of melt from olivine-free pyroxenite mainly depends on the melting modes of garnet and clinopyroxene. If garnet exists as a residual mineral, the melt is always isotopically heavier $(\sim 0.05 \%)$ in its magnesium composition than its source. When at higher pressure clinopyroxene becomes the residual mineral, the melt is $\sim 0.01 \%$ lighter than its source. Such predictions make $\delta^{25} \mathrm{Mg}$ values of OIB samples a temping tracer of mantle heterogeneity.

[1] Teng et al. (2010) GCA 74, 4150-4166. [2] Schauble et al. (2011). GCA 75, 844-869. [3] Pogge van Strandmann et al. (2011). GCA 75, 5247-5268. [4] Coath et al. (2017) Chemical Geology 451, 78-89. [5] Liu et al. (2021) GCA under review 